\title{
Secondary prevention of fragility fractures: instrumental role of a fracture liaison service to tackle the risk of imminent fracture
}

\author{
Ronald MY Wong, SW Law, KB Lee, Simon KH Chow *, WH Cheung
}

\section{A B S T R A C T}

The occurrence of fragility fractures is strongly associated with significant morbidity and mortality. Effective recommendations should be set to treat these patients punctually for secondary prevention of fractures and ultimately decrease healthcare costs. The key pitfalls in the current management for patients with fragility fractures are the lack of fracture liaison services, low prescription rates for osteoporosis, inadequate referral for rehabilitation, and low follow-up attendance leading to poor compliance with treatment. Most imminent fractures occur within the first 2 years, and it is therefore important to raise the awareness of fracture risk and provide fracture liaison services to improve management. Fracture liaison services are coordinated and have been shown to be costeffective. These services allow prompt identification of patients with fragility fractures. This leads to appropriate investigations of their bone health and fall risk. Information about and interventions for each patient are provided for secondary prevention of fractures. Implementation of the fracture liaison services model would play a major role in improving patient outcomes in our community.

\author{
Hong Kong Med J 2019;25:235-42 \\ https://doi.org/10.12809/hkmj187593 \\ ${ }^{1}$ RMY Wong, MB, ChB, PhD \\ ${ }^{2}$ SW Law, MB, ChB, FHKAM (Orthopaedic Surgery) \\ ${ }^{3}$ KB Lee, FRCSEd (Ortho), FHKAM (Orthopaedic Surgery) \\ ${ }^{1}$ SKH Chow *, PhD \\ WH Cheung, PhD
}

1 Department of Orthopaedics and Traumatology, The Chinese University of Hong Kong, Shatin, Hong Kong

2 Department of Orthopaedics and Traumatology, Prince of Wales Hospital, Shatin, Hong Kong

${ }^{3}$ Department of Orthopaedics and Traumatology, Queen Elizabeth Hospital, Jordan, Hong Kong

* Corresponding author: skhchow@ort.cuhk.edu.hk

\section{Introduction}

Osteoporosis is a socio-economic threat, and with the ageing population, the disease has grown into a global epidemic. The lifetime fracture risk in patients with osteoporosis can reach $40 \%$, and the most common fracture regions are the hip, distal radius, and spine. ${ }^{1}$ In Hong Kong, the number of fragility fractures is on the rise, and hospital budgets are increasing. Currently, around 6000 hip fractures occur annually in Hong Kong, and these numbers are projected to double by $2050 .^{2}$ A recent study showed that the number of hip fractures in Asia will increase from 1124060 in 2018 to 2563488 in 2050, a 2.28 -fold increase. ${ }^{3}$ It is also expected that $50 \%$ of hip fractures will occur in Asia, with the majority in China. ${ }^{4}$

According to the Osteoporosis Society of Hong Kong, 95\% of direct costs of osteoporosis are incurred for acute management and rehabilitation of the fracture. ${ }^{5}$ Annual hospital expenditures for hip fractures in Hong Kong amount to approximately US\$52 million and rising. ${ }^{6}$

The occurrence of fragility fractures is strongly associated with significant morbidity and mortality. Mortality after a hip fracture is around $5 \%$ to $10 \%$ after
1 month, and one-third of patients die by 1 year. ${ }^{7}$ At least $10 \%$ of patients have care issues, and most have residual disability and pain. Many studies have also shown that mortality after vertebral compression fractures is almost as high as that after hip fractures. ${ }^{8}$ More importantly, after the occurrence of the first fracture, prompt measures and initiatives should be taken for secondary prevention to decrease healthcare costs.

The single most predictive factor of a fragility fracture is the presence of a previous fracture. The relative risk is approximately 2 -fold higher to sustain a hip or vertebral fracture after a prior fragility fracture. The risk of vertebral fracture is 4-fold higher for patients with prior vertebral fractures than for those without. ${ }^{9}$ The increased relative risk is not constant with time or age, as imminent fractures occur shortly after the initial one. ${ }^{10} \mathrm{~A}$ previous large-scale prospective cohort study in Australia showed that absolute repeat fracture risk persists up to 10 years and that $40 \%$ to $60 \%$ of surviving patients experience a subsequent fracture. However, $41 \%$ of refractures in women and $52 \%$ of refractures in men occur within the first 2 years. ${ }^{11}$ Effective recommendations should be made to treat 
脆性骨折的二次預防：骨折聯絡服務降低二次 骨折風險的作用

\section{黃文揚、羅尚尉、李建邦、周冠豪、張穎愷}

脆性骨折有極高的發病率和死亡率。對於這類患者應給予及時有效 的二次骨折預防的相關指導, 從而最終減輕醫療負擔。目前關於脆性 骨折患者管理最主要的問題在於缺乏骨折聯絡服務、骨質疏鬆處方率 低、康復轉介缺乏，以及低隨訪率導致的依從性不高等。大部份的二 次骨折發生在首次骨折後兩年內, 因此提高患者的骨折預防意識並提 供有效骨折聯絡服務對這類患者的管理很重要。骨折聯絡服務是一項 多部門相互協調且能實現最大效益的措施。這些服務首先可以及時識 別脆性骨折患者, 繼而能夠對他們的骨骼健康和跌倒風險進行有效評 估。因此通過整合患者資料並採取相應干預措施可有效預防二次骨 折。骨折聯絡服務對改善本地骨折患者的治療成效非常重要。 these patients punctually for secondary prevention of fractures and ultimately decrease healthcare costs in Hong Kong.

This guideline serves to provide recommendations about identifying patients with risk of imminent fracture. Prompt management with the incorporation of fracture liaison services (FLS) based on a review of the current literature is provided.

\section{Pitfalls in Hong Kong's current fragility fracture management}

The PubMed database (date last accessed: 28 October 2018) was searched. The keywords used for the search criteria were "fragility fracture" and "Hong Kong" and "manage". Seven studies were retrieved in the initial search. From these results, four studies related to the management of fragility fractures in Hong Kong were included. ${ }^{12-15}$ The remaining studies were unrelated and excluded. The key pitfalls in the current management of patients with fragility fractures in Hong Kong are the lack of FLS (10\%$25 \%$ in public hospitals), low prescription rates for osteoporosis on discharge (23\% of hip fracture cases), inadequate referral rates for rehabilitation (22\% of hip fracture cases), and low follow-up attendance (35.1\% of hip fracture cases at 1 year). It is therefore important to raise awareness about imminent fractures and FLS to further improve the current management situation.

Currently, there is a large treatment gap between osteoporotic fractures and secondary prevention. According to the International Osteoporosis Foundation (IOF), only $10 \%$ to $25 \%$ of public hospitals in Hong Kong have FLS. ${ }^{6}$ Furthermore, a study of six hospitals in Hong Kong located in different clusters showed that only $23 \%$ of patients were prescribed anti-osteoporotic medications postoperatively for hip fractures. ${ }^{15}$ Another study showed that $33 \%$ of anti-osteoporotic medications that were prescribed were given 6 months after discharge. ${ }^{14}$ Routine preoperative orthogeriatric comanagement for hip fractures was given in only 3.5\% of cases. ${ }^{15}$ A previous study had already established certain outcomes, showing a shorter length of stay, shorter time to surgery, lower in-hospital mortality, and lower hospital cost of US\$170224 annually with implementation of an orthogeriatric intervention for hip fracture patients in Hong Kong. ${ }^{16}$ Currently, there is poor coordination among different subspecialties in delivery of post-fragility fracture care. There is also low follow-up attendance after discharge: $74.8 \%$ at 3 months and $35.1 \%$ at 1 year. ${ }^{15}$ Internal surveys showed only $22 \%$ of patients are referred for rehabilitation, with inadequate fall prevention programmes provided.

As the number of patients with osteoporosis continues to grow, regular follow-up is crucial, as long-term monitoring for chronic disease is required. Currently, fewer than five public hospitals have dedicated osteoporosis clinics for care of these patients. More importantly, many patients are seen at various subspecialty clinics, including general medicine, orthopaedics, endocrinology, and geriatrics, causing the standard of care to be suboptimal.

There are currently seven dual-energy X-ray absorptiometry (DXA) scanning facilities in the public setting in Hong Kong. The average waiting time for a DXA scan is 1 to 6 years, depending on location. The long waiting time places the patient at high risk of imminent fractures occurring within 2 years of the initial fracture.

According to the Asian Federation of Osteoporosis Societies Call-To-Action Committee, osteoporosis should be made a national health priority. ${ }^{17}$ It is also important to raise public awareness, have educational programmes for health professionals, and ultimately prevent secondary fractures. The current evidence suggests that a structured service delivery model (ie, an FLS) is therefore essential to improve the care of our patients. There is certainly a pressing need for further resource allocation to the prevention of secondary fractures to decrease healthcare costs, patient morbidity, and mortality.

\section{Preventing imminent fractures}

Imminent fractures, or fractures occurring within 2 years of the initial fracture, should be identified promptly to receive anti-osteoporotic treatment and fall prevention programmes. ${ }^{10,18}$ Prompt multidisciplinary assessment should be employed, and patients should undergo thorough evaluation to prevent imminent fractures. It is well documented that the cause of imminent fractures may be the 
increase of frailty during hospital admission. ${ }^{18}$ Immobility due to pain and disability causes an increased loss of cortical and trabecular bone.

The Reykjavik Study fracture registrar from Iceland showed that the risk of a major osteoporotic fracture after a previous one was 2.7-fold higher compared with the general population risk at 1 year, and this risk elevation decreases to 1.4-fold at 10 years. ${ }^{10}$ The risk of a second major osteoporotic fracture also increases by $4 \%$ for each year of age. As the absolute risk is $6.1 \%$ for subsequent fractures at 1 year, the implementation of global fracture prevention strategies to prevent imminent fractures is crucial. ${ }^{10}$ The concept of a recent fracture as a more predictive risk factor than fracture history is important for future health policies. ${ }^{10,19}$ Therefore, the window of opportunity to treat imminent fractures is best taken advantage of by FLS, as it provides a holistic approach and treats osteoporosis from a public health perspective. ${ }^{20}$

\section{Importance and cost-effectiveness of fracture liaison services for patients with fragility fractures}

Fracture liaison services are coordinated services that identify patients with fragility fractures, assess and treat their bone health, make referrals for rehabilitation, and aim to prevent secondary fractures. $^{21}$

Most patients do not receive appropriate bone health assessment and treatment. In fact, only $9 \%$ to $50 \%$ of patients in the US, the UK, and Canada proceed with these assessments after a fragility fracture. ${ }^{21}$ International FLS guidelines in the US including initiatives by specialty groups, such as the American Orthopedics Association "Own the Bone" campaign, have been established to target these patients during the imminent fracture time interval. ${ }^{22}$ In a US nationwide study of 273330 patients with index fractures, imminent fractures were common in the 1 year following hip, shoulder or wrist fractures. Therefore, national strategies to minimise further impairment have been urged, as subsequent fractures cause significant morbidity and loss of quality of life. However, many hospitals worldwide still lack this model of care. ${ }^{23,24}$

A recent meta-analysis of 74 controlled studies showed that FLS programmes improved outcomes, with significant increases in bone mineral density assessment (48.0\% vs $23.5 \%)$, treatment initiation (38.0\% vs $17.2 \%)$ and adherence $(57.0 \%$ vs $34.1 \%)$, and reductions in re-fracture incidence (6.4\% vs $13.4 \%)$ and mortality $(10.4 \%$ vs $15.8 \%) .{ }^{25}$ In Taiwan, 22 FLS programmes have already been established, of which 11 are accredited by the IOF. ${ }^{26}$ Taiwan has some of the best FLS coverage in the Asia-Pacific region. Randomised controlled trials are being conducted to assess outcomes in Taiwan. ${ }^{26}$ Other countries that have adopted FLS programmes include Japan, where it has been proven to be cost-effective. A recent study in Japan showed an additional lifetime cost of US\$3396 per person for an additional 0.118 quality-adjusted life year (QALY), resulting in an incremental cost-effectiveness ratio of US $\$ 28880$ per QALY gained. ${ }^{27}$ Furthermore, a systematic review has also shown that FLS per the IOF Best Practice Standards conducted in Canada, Australia, the US, the UK, Japan, and Sweden were all found to be costeffective in comparison with usual or no treatment, regardless of programme intensity or country. ${ }^{24}$ The costs per QALY ranged from US $\$ 3023$ to US\$28 800 in Japan and from US\$14513 to US\$112 877 in the US. Several studies have also shown that FLS was cost-saving, which further reinforces that these services should be widely adopted and introduced. ${ }^{24}$ Fracture liaison services could effectively bridge the gap between the patient and prevention of imminent fractures.

\section{Creating a model for fracture liaison services in Hong Kong}

There are several published models to create an effective model of FLS care. Many hospitals have adopted the recommendations of the IOF Capture the Fracture Campaign, which consist of 13 Best Practice Standards. ${ }^{28}$ The recent FLS consensus meeting in the Asia-Pacific Region endorsed by the IOF, the Asian Federation of Osteoporosis Societies, and the Asia Pacific Osteoporosis Foundation reinforced that there is still a wide gap in terms of fragility fractures and secondary prevention. ${ }^{12}$

Therefore, it is essential to establish FLS in Hong Kong (Fig). One essential element is a dedicated coordinator, often a nurse ${ }^{29}$ who provides proactive recruitment of patients aged $\geq 50$ years with new fragility fractures or vertebral fractures. All patients should be evaluated for future fracture risk within 3 months. In addition to DXA scanning, the cause of osteoporosis should also be recognised, and blood tests including serum calcium, phosphate, creatinine, and 25-hydroxyvitamin D should be performed to look for secondary osteoporosis. All patients with osteoporosis should be treated promptly with antiosteoporotic medications and reviewed regularly during follow-up. Fall risk and health and lifestyle risk factors should be evaluated accordingly. A dedicated database with long-term management should be established for these patients.

The implementation of an FLS model would play a major role in improving patient outcomes to prevent imminent fractures. It is important to have policymaker and stakeholder engagement to achieve successful and widespread uptake of FLS in our community. 


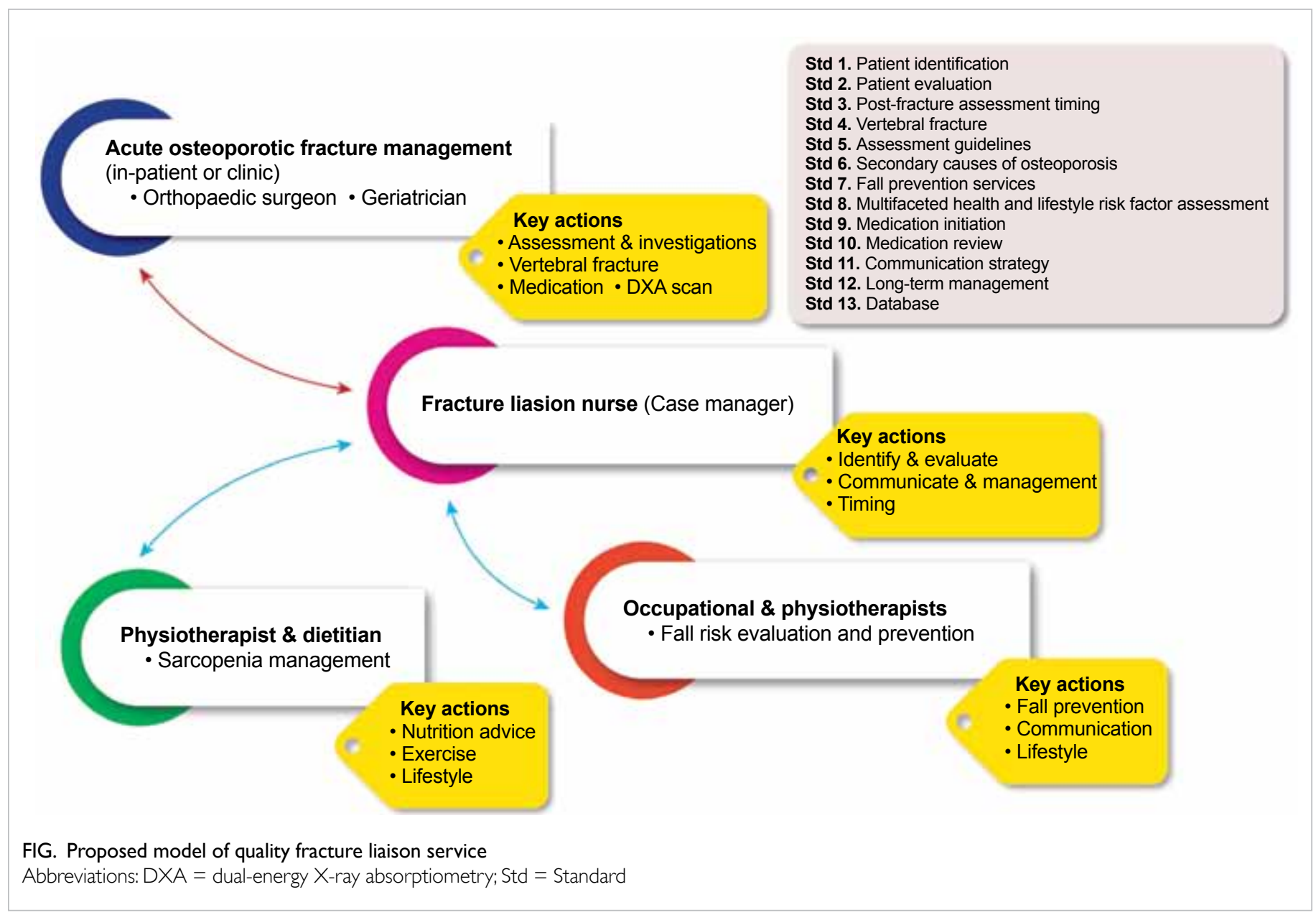

\section{Anti-osteoporotic drug use and challenges in decreasing imminent fractures}

In Hong Kong, only $23 \%$ of hip patients discharged are prescribed with anti-osteoporotic medications, excluding calcium and vitamin D supplements. ${ }^{15}$ An FLS model would be important to coordinate and improve on osteoporosis medication initiation and adherence and improve follow-up. ${ }^{30}$ Bisphosphonates are most commonly prescribed and are currently considered first-line drugs for treatment of osteoporosis. ${ }^{5}$ The Agency for Healthcare Research and Quality published a systematic review showing alendronate, risedronate, zoledronic acid, denosumab and teriparatide to be effective at reducing fractures. ${ }^{31}$ This further shows the importance of early treatment to prevent imminent fractures. A meta-analysis of 10 studies of five anti-osteoporotic agents (risedronate, alendronate, strontium ranelate, zoledronic acid, and denosumab) also showed an $11 \%$ reduction in mortality with treatment for established fragility fractures. Mortality reduction was highest in patients who were frail and older. ${ }^{32}$ The Table summarises a selection of anti-osteoporotic drugs.

Currently, the prescription of combination treatment has a low quality of evidence, except for the addition of teriparatide to on-going denosumab, which produces a large increase in bone mineral density compared with monotherapy. ${ }^{33}$ The use of bisphosphonates following teriparatide has been shown to produce an additional bone mineral density increase in both the hip and spine. ${ }^{33,34}$ Sequential anabolic drugs followed by anti-remodelling agents may therefore become the standard to treat imminent fractures in the future. ${ }^{35}$

However, poor compliance with bisphosphonates is a major issue worldwide. ${ }^{18}$ Additional measures to tackle this problem are essential to ensure successful patient care during the period of imminent fractures.

\section{Improving compliance with bisphosphonates}

A systematic review has shown that $50 \%$ of all patients prescribed oral bisphosphonates stop treatment within 1 year. ${ }^{18,36}$ Although patients receiving weekly instead of daily oral bisphosphonates had higher 
TABLE. Summary of anti-osteoporotic drugs

\begin{tabular}{|c|c|c|c|c|c|}
\hline Parameters & ZOL & ALN & RIS & PTH & DMAb \\
\hline \multicolumn{6}{|l|}{ Anti-fracture efficacy } \\
\hline Vertebral fracture & $-70 \%$ & $-45 \%$ & $-39 \%$ & $-65 \%$ & $-68 \%$ \\
\hline Non-vertebral fracture & $-25 \%$ & $-23 \%$ & $-20 \%$ & $-53 \%$ & $-20 \%$ \\
\hline Hip fracture & $-41 \%$ & $-53 \%$ & $-26 \%$ & ND & $-40 \%$ \\
\hline Survival benefit & $28 \%$ & Obs & Obs & ND & ND \\
\hline CV risk & $\pm \mathrm{AF}$ & $\pm \mathrm{AF}$ & $\pm \mathrm{AF}$ & Nil & Nil \\
\hline $\begin{array}{l}\text { Safely administered in patients with CKD } \\
\text { (eGFR } \mathrm{mL} / \mathrm{min} \text { ) }\end{array}$ & $>35$ & $>30$ & $>30$ & ND & No contra-indication \\
\hline Frequency of administration & Yearly & Weekly & Monthly/weekly & Daily & 6-Monthly \\
\hline
\end{tabular}

Abbreviations: $\mathrm{AF}=$ atrial fibrillation; $\mathrm{ALN}=$ alendronate; $\mathrm{CKD}$ = chronic kidney disease; $\mathrm{CV}$ = cardiovascular; $\mathrm{DMAb}=$ denosumab; eGFR = estimated glomerular filtration rate; ND = No data; Obs = observational study; PTH = parathyroid hormone; RIS = risedronate; $\mathrm{ZOL}=$ zoledronate

compliance at 1 year, the overall treatment rate was still below the required standard for optimal fracture prevention. ${ }^{37}$ A meta-analysis of 15 articles describing 171063 patients revealed a $46 \%$ increase of fracture risk in non-compliant patients compared with compliant patients. ${ }^{38}$ Adherence to bisphosphonates has become a major problem leading to subsequent fractures, morbidity, and mortality.

International guidelines to improve adherence have been recommended. A systematic review showed that periodic follow-up interaction between patients and health professionals improved adherence and persistence.$^{39}$ A review of 20 studies showed the importance of simplification of the dosing regimen. ${ }^{40}$ The Denosumab Adherence Preference Satisfaction study, a 24-month randomised, crossover comparison with alendronate in postmenopausal women, showed less frequent non-adherence with denosumab, which was injected every 6 months. ${ }^{41}$ Of the 250 women who enrolled, at 1 year and 2 years, $88.1 \%$ and $92.5 \%$ adhered to denosumab, whereas only $76.6 \%$ and $63.5 \%$ adhered to alendronate, respectively. Furthermore, of the 198 subjects who expressed treatment preference, $92.4 \%$ favoured injections over oral therapy. ${ }^{41}$ A US study consisting of 10863 patients with newly initiated osteoporosis treatment showed that at 12 months of treatment, persistence varied from $28.9 \%$ to $35.1 \%$ for oral bisphosphonate users, $59.1 \%$ for teriparatide, and $68.3 \%$ for denosumab. ${ }^{42}$ Although there has been no comparison between denosumab and zoledronic acid, recent reviews have shown that adherence to and patient preference for zoledronic acid were greater compared with that for oral bisphosphonates. ${ }^{43}$ This further reinforces that patients prefer less frequent dosing and that switching from oral to injection therapy may improve compliance. ${ }^{44}$

Prescribing anti-osteoporotic drugs that have higher compliance is an important consideration for clinicians, especially during the first 2 years, when imminent fracture risk is high.

\section{Fall prevention programmes to prevent imminent fractures}

Numerous studies have concluded that among elderly people, fall prevention is as important as treating osteoporosis. ${ }^{45}$ It is estimated that fall prevention reduces the number of fractures by over $50 \%$. Fracture liaison services models have recommended assessment of fall risk, which is essential to prevent imminent fractures. Early referral for physiotherapy and exercise-based intervention (including multicomponent exercises with strength, endurance, and balance training) reduces the rate and risk of falling. ${ }^{46}$ Balance training is also an important component of fall prevention for patients with fragility fractures during rehabilitation. Tai chi has been shown to significantly reduce fall risk and rate. ${ }^{47}$

A recent systematic review and meta-analysis showed that vibration therapy reduced fall rate and may prevent fractures by reducing falls. ${ }^{48}$ Vibration therapy provides a non-invasive, cyclic mechanical stimulation that has been shown to improve quadriceps muscle strength, balancing, and movement velocity. ${ }^{49}$ Incorporating the device into multidisciplinary rehabilitation programmes for elderly patients with hip fractures has also been shown to be effective. ${ }^{13}$ The FLS programme is able to integrate fall risk assessments with adequate information and treatment for patients to prevent further falls and fractures, especially during the imminent fracture period.

\section{Increasing awareness of sarcopenia and fragility fractures}

Sarcopenia is an age-related decline in muscle bulk and strength, which is strongly associated with 
frailty. ${ }^{50}$ According to the practical definition and consensus for age-related sarcopenia in 2010 by the European Working Group on Sarcopenia in Older People and in 2014 by the Asian Working Group for Sarcopenia, low muscle mass and low muscle function or low physical performance are the criteria for diagnosis. ${ }^{51,52}$

Sarcopenia leads to falls, disability, and increased mortality. More importantly, a recent multi-centre cross-sectional study showed that $37 \%$ of subjects with hip fractures were diagnosed with sarcopenia. ${ }^{53}$ Several studies have shown that osteoporosis is closely related to sarcopenia. ${ }^{54} \mathrm{~A}$ study of 2400 Japanese women also showed sarcopenia was highly associated with osteopenia (present in 16.8\% of cases) and osteoporosis (in 20.4\%). ${ }^{55}$

A local study showed that the prevalence of sarcopenia was $73.6 \%$ in men and $67.7 \%$ in women with geriatric hip fractures. ${ }^{56}$ This prevalence is much higher than that in community-dwelling elderly people, and therefore, the health status of muscle tissue should be investigated during hospitalisation..$^{51}$ A global evaluation of nutritional status is required in addition to early mobilisation of patients. Resistance exercises and supplements including vitamin D should be recommended to strengthen muscle and hence reduce falls. ${ }^{57,58}$ Studies have also shown that nutrition is important for sarcopenia and that protein intake of 1.0 to $1.2 \mathrm{~g} / \mathrm{kg}$ per day is recommended for older adults..$^{59}$ Dietary protein increases insulin-like growth factor, which has anabolic effects on bone and muscle. Furthermore, calcium absorption is increased, having positive effects on bone health. ${ }^{59}$ Awareness and understanding of the condition are crucial for better care and quality of life for elderly patients.

\section{Recommendation to establish fracture liaison services in Hong Kong}

Once an official FLS programme is established in Hong Kong based on the 13 best practice standards, serial workshops should be hosted to promote FLS expansion by a panel of local experts. ${ }^{26}$ Experts should be invited as clinical instructors and coordinators to share experiences. New programmes can also share challenges and interim progress for discussion. Furthermore, osteoporosis treatment promotion events can be held at each participating hospital to allow close interactions between healthcare providers and patients. After successful implementation, accreditation by the IOF can be achieved based on assessment of the practice guidelines. ${ }^{60}$

\section{Conclusion}

Fracture liaison service models should be adopted in hospitals for secondary prevention of fractures, particularly imminent fractures. Fracture liaison services can improve patient outcomes and decrease healthcare costs. With the current lack of resources and pitfalls in fragility fracture management in Hong Kong, major changes and engagement with stakeholders are crucial to achieve successful and widespread uptake of FLS to tackle the undertreatment of osteoporosis.

\section{Author contributions}

All authors had full access to the data, contributed to the study, approved the final version for publication, and take responsibility for its accuracy and integrity.

Concept and design of study: All authors.

Acquisition of data: RMY Wong, SKH Chow, WH Cheung. Drafting of the manuscript: RMY Wong, SW Law, WH Cheung.

Critical revision for important intellectual content: KB Lee, SKH Chow.

\section{Conflicts of interest}

All authors have disclosed no conflicts of interest.

\section{Funding/support}

This research received no specific grant from any funding agency in the public, commercial, or not-for-profit sectors.

\section{References}

1. Rachner TD, Khosla S, Hofbauer LC. Osteoporosis: now and the future. Lancet 2011;377:1276-87.

2. Lau PY. To improve the quality of life in elderly people with fragility fractures. Hong Kong Med J 2016;22:4-5.

3. Cheung CL, Ang SB, Chadha M, et al. An updated hip fracture projection in Asia: The Asian Federation of Osteoporosis Societies study. Osteoporos Sarcopenia 2018;4:16-21.

4. Bow CH, Tsang SW, Loong CH, Soong CS, Yeung SC, Kung AW. Bone mineral density enhances use of clinical risk factors in predicting ten-year risk of osteoporotic fractures in Chinese men: the Hong Kong Osteoporosis Study. Osteoporosis Int 2011;22:2799-807.

5. OSHK Task Group for Formulation of 2013 OSHK Guideline for Clinical Management of Postmenopausal Osteoporosis in Hong Kong; Ip TP, Cheung SK, Cheung TC, et al. The Osteoporosis Society of Hong Kong (OSHK): 2013 OSHK guideline for clinical management of postmenopausal osteoporosis in Hong Kong. Hong Kong Med J 2013;19 Suppl 2:1-40.

6. International Osteoporosis Foundation. Asia-Pacific regional audit. Epidemiology, costs, and burden of osteoporosis in 2013-Hong Kong. Available from: https:// www.iofbonehealth.org/sites/default/files/media/PDFs/ Regional\%20Audits/2013-Asia_Pacific_Audit-Hong_ Kong_0_0.pdf. Accessed 1 Jul 2018.

7. Parker M, Johansen A. Hip fracture. BMJ 2006;333:27-30.

8. Johnell O, Kanis JA, Odén A, et al. Mortality after osteoporotic fractures. Osteoporos Int 2004;15:38-42.

9. Klotzbuecher CM, Ross PD, Landsman PB, Abbott TA 3rd, Berger M. Patients with prior fractures have an increased 
risk of future fractures: a summary of the literature and statistical synthesis. J Bone Miner Res 2000;15:721-39.

10. Johansson H, Siggeirsdóttir K, Harvey NC, et al. Imminent risk of fracture after fracture. Osteoporos Int 2017;28:77580.

11. Center JR, Bliuc D, Nguyen TV, Eisman JA. Risk of subsequent fracture after low-trauma fracture in men and women. JAMA 2007;297:387-94.

12. Chan DD, Chang LY, Akesson KE, et al. Consensus on best practice standards for Fracture Liaison Service in the AsiaPacific region. Arch Osteoporos 2018;13:59.

13. Cheung WH, Shen WY, Dai DL, et al. Evaluation of a multidisciplinary rehabilitation programme for elderly patients with hip fracture: a prospective cohort study. J Rehabil Med 2018;50:285-91.

14. Kung AW, Fan T, Xu L, et al. Factors influencing diagnosis and treatment of osteoporosis after a fragility fracture among postmenopausal women in Asian countries: a retrospective study. BMC Womens Health 2013;13:7.

15. Leung KS, Yuen WF, Ngai WK, et al. How well are we managing fragility hip fractures? A narrative report on the review with the attempt to set up a Fragility Fracture Registry in Hong Kong. Hong Kong Med 2017;23:264-71.

16. Ho WW, Dai DL, Liu KW, et al. To investigate the effect and cost-effectiveness of implementing an orthogeriatric intervention for elderly patients with acute hip fracture: the experience in Hong Kong. J Am Geriatr Soc 2009;57:21534.

17. Yeap SS, Jaisamrarn U, Park YS, Takeuchi Y, Xia W, AFOS Call-To-Action Committee. The Asian Federation of Osteoporosis Societies' call to action to improve the undertreatment of osteoporosis in Asia. Osteoporos Sarcopenia 2017;3:161-3.

18. Roux C, Briot K. Imminent fracture risk. Osteoporos Int 2017;28:1765-9.

19. O'Hanlon CE, Parthan A, Kruse M, et al. A model for assessing the clinical and economic benefits of boneforming agents for reducing fractures in postmenopausal women at high, near-term risk of osteoporotic fracture. Clin Ther 2017;39:1276-90.

20. Noordin S, Allana S, Masri BA. Establishing a hospital based fracture liaison service to prevent secondary insufficiency fractures. Int J Surg 2018;54(Pt B):328-32.

21. Walters S, Khan T, Ong T, Sahota O. Fracture liaison services: improving outcomes for patients with osteoporosis. Clin Interv Aging 2017;12:117-27.

22. Bynum JP, Bell JE, Cantu RV, et al. Second fractures among older adults in the year following hip, shoulder, or wrist fracture. Osteoporosis Int 2016;27:2207-15.

23. Huntjens KM, van Geel TA, van den Bergh JP, et al. Fracture liaison service: impact on subsequent nonvertebral fracture incidence and mortality. J Bone Joint Surg Am 2014;96:e29.

24. Wu CH, Kao IJ, Hung WC, et al. Economic impact and cost-effectiveness of fracture liaison services: a systematic review of the literature. Osteoporos Int 2018;29:1227-42.

25. Wu CH, Tu ST, Chang YF, et al. Fracture liaison services improve outcomes of patients with osteoporosis-related fractures: a systematic literature review and meta-analysis. Bone 2018;111:92-100.

26. Chang LY, Tsai KS, Peng JK, et al. The development of Taiwan Fracture Liaison Service network. Osteoporos Sarcopenia 2018;4:47-52.

27. Moriwaki K, Noto S. Economic evaluation of osteoporosis liaison service for secondary fracture prevention in postmenopausal osteoporosis patients with previous hip fracture in Japan. Osteoporos Int 2017;28:621-32.

28. Akesson K, Marsh D, Mitchell PJ, et al. Capture the Fracture: a Best Practice Framework and global campaign to break the fragility fracture cycle. Osteoporos Int 2013;24:2135-52.

29. Ganda K, Puech M, Chen JS, et al. Models of care for the secondary prevention of osteoporotic fractures: a systematic review and meta-analysis. Osteoporos Int 2013;24:393-406.

30. Yates CJ, Chauchard MA, Liew D, Bucknill A, Wark JD. Bridging the osteoporosis treatment gap: performance and cost-effectiveness of a fracture liaison service. J Clin Densitom 2015;18:150-6.

31. Levis S, Theodore G. Summary of AHRQ's comparative effectiveness review of treatment to prevent fractures in men and women with low bone density or osteoporosis: update of the 2007 report. J Manag Care Pharm 2012;18(4 Suppl B):S1-15.

32. Bolland MJ, Grey AB, Gamble GD, Reid IR. Effect of osteoporosis treatment on mortality: a meta-analysis. J Clin Endocrinol Metab 2010;95:1174-81.

33. McClung MR. Using osteoporosis therapies in combination. Curr Osteoporos Rep 2017;15:343-52.

34. Black DM, Bilezikian JP, Ensrud KE, et al. One year of alendronate after one year of parathyroid hormone (1-84) for osteoporosis. N Engl J Med 2005;353:555-65.

35. Cosman F, Nieves JW, Dempster DW. Treatment sequence matters: anabolic and antiresorptive therapy for osteoporosis. J Bone Miner Res 2017;32:198-202.

36. Maraka S, Kennel KA. Bisphosphonates for the prevention and treatment of osteoporosis. BMJ 2015;351:h3783.

37. Rabenda V, Mertens R, Fabri V, et al. Adherence to bisphosphonates therapy and hip fracture risk in osteoporotic women. Osteoporos Int 2008;19:811-8.

38. Imaz I, Zegarra P, González-Enríquez J, Rubio B, Alcazar R, Amate JM. Poor bisphosphonate adherence for treatment of osteoporosis increases fracture risk: systematic review and meta-analysis. Osteoporos Int 2010;21:1943-51.

39. Gleeson T, Iversen MD, Avorn J, et al. Interventions to improve adherence and persistence with osteoporosis medications: a systematic literature review. Osteoporos Int 2009;20:2127-34.

40. Hiligsmann M, Salas M, Hughes DA, et al. Interventions to improve osteoporosis medication adherence and persistence: a systematic review and literature appraisal by the ISPOR Medication Adherence \& Persistence Special Interest Group. Osteoporos Int 2013;24:2907-18.

41. Freemantle N, Satram-Hoang S, Tang ET, et al. Final results of the DAPS (Denosumab Adherence Preference Satisfaction) study: a 24-month, randomized, crossover comparison with alendronate in postmenopausal women. Osteoporos Int 2012;23:317-26.

42. Cheng LI, Durden E, Limone B, et al. Persistence and compliance with osteoporosis therapies among women in a commercially insured population in the United States. J Manag Care Spec Pharm 2015;21:824-33, 833a.

43. Lozano MJ, Sánchez-Fidalgo S. Adherence and preference of intravenous zoledronic acid for osteoporosis versus other bisphosphonates. Eur J Hosp Pharm 2019;26:4-9.

44. Dalle Carbonare L, Zanatta M, Gasparetto A, Valenti MT. Safety and tolerability of zoledronic acid and other 
bisphosphonates in osteoporosis management. Drug Healthc Patient Saf 2010;2:121-37.

45. Jarvinen TL, Sievänen H, Khan KM, Heinonen A, Kannus P. Shifting the focus in fracture prevention from osteoporosis to falls. BMJ 2008;336:124-6.

46. Vieira ER, Palmer RC, Chaves PH. Prevention of falls in older people living in the community. BMJ 2016;353:i1419.

47. Gillespie LD, Robertson MC, Gillespie WJ, et al. Interventions for preventing falls in older people living in the community. Cochrane Database Syst Rev 2012;(9):CD007146.

48. Jepsen DB, Thomsen K, Hansen S, Jørgensen NR, Masud T, Ryg J. Effect of whole-body vibration exercise in preventing falls and fractures: a systematic review and meta-analysis. BMJ Open 2017;7:e018342.

49. Leung KS, Li CY, Tse YK, et al. Effects of 18-month low-magnitude high-frequency vibration on fall rate and fracture risks in 710 community elderly-a clusterrandomized controlled trial. Osteoporos Int 2014;25:178595.

50. Hong W, Cheng Q, Zhu X, et al. Prevalence of sarcopenia and its relationship with sites of fragility fractures in elderly Chinese men and women. PloS One 2015;10:e0138102.

51. Tarantino U, Piccirilli E, Fantini M, Baldi J, Gasbarra E, Bei R. Sarcopenia and fragility fractures: molecular and clinical evidence of the bone-muscle interaction. J Bone Joint Surg Am 2015;97:429-37.

52. Chen LK, Liu LK, Woo J, et al. Sarcopenia in Asia: consensus report of the Asian Working Group for Sarcopenia. J Am
Med Dir Assoc 2014;15:95-101.

53. Steihaug OM, Gjesdal CG, Bogen B, Kristoffersen MH, Lien G, Ranhoff AH. Sarcopenia in patients with hip fracture: a multicenter cross-sectional study. PloS One 2017;12:e0184780.

54. Tarantino U, Baldi J, Scimeca M, et al. The role of sarcopenia with and without fracture. Injury 2016;47 Suppl 4:S3-10.

55. Miyakoshi N, Hongo M, Mizutani Y, Shimada Y. Prevalence of sarcopenia in Japanese women with osteopenia and osteoporosis. J Bone Miner Metab 2013;31:556-61.

56. Ho AW, Lee MM, Chan EW, et al. Prevalence of presarcopenia and sarcopenia in Hong Kong Chinese geriatric patients with hip fracture and its correlation with different factors. Hong Kong Med J 2016;22:23-9.

57. Roth SM, Ferrell RF, Hurley BF. Strength training for the prevention and treatment of sarcopenia. J Nutr Health Aging 2000;4:143-55.

58. Mithal A, Bonjour JP, Boonen S, et al. Impact of nutrition on muscle mass, strength, and performance in older adults. Osteoporos Int 2013;24:1555-66.

59. Gaffney-Stomberg E, Insogna KL, Rodriguez NR, Kerstetter JE. Increasing dietary protein requirements in elderly people for optimal muscle and bone health. J Am Geriatr Soc 2009;57:1073-9.

60. International Osteoporosis Foundation. Does your fracture liaison service deserve gold-star recognition? 2014. Available from: https://www.iofbonehealth.org/ news/does-your-fracture-liaison-service-deserve-goldstar-recognition. Accessed 1 Jul 2018. 